\title{
PADRÕES DE FINANCIAMENTO DOS MUNICÍPIOS: UMA AVALIAÇÃO PELA ÓTICA DA HIERARQUIA DOS CENTROS URBANOS
}

\author{
MUNICIPAL FINANCING STANDARDS: AN ASSESSMENT FROM THE PERSPECTIVE OF URBAN CENTERS HIERARCHY
}

\section{RESUMO}

Buscando captar padrões de financiamento dos municípios brasileiros, classificados segundo a lógica da hierarquia dos centros urbanos do IBGE, esse artigo apresentou uma análise intertemporal do financiamento local a partir da construção de indicadores fiscais propostos por Cialdini e Afonso (2014). Os resultados corroboram percepções consolidadas sobre o tema, como a alta dependência de transferências intergovernamentais pelos municípios de pequeno porte e o maior esforço fiscal dos municípios de maior porte, mas também trazem informações novas relativas ao uso de instrumentos de empréstimo (operações de crédito) e do nível de liquidez dos governos locais. Apesar do exercício ter sido aplicado para um período no qual o país vivenciou uma crise econômica, não foi possível observar um impacto desse evento nos indicadores, sugerindo que esse padrão de financiamento captado pelo estudo tem um elemento estrutural muito forte, que é pouco sensível ao ciclo econômico ou mesmo político (eleitoral).

Palavras-chave: município; financiamento; receita fiscal; hierarquia urbana.

\section{ABSTRACT}

Seeking to capture financing patterns of Brazilian municipalities, classified according to IBGE's logic of the hierarchy urban centers, this article presented an intertemporal analysis of local financing from the construction of fiscal indicators proposed by Cialdini and Afonso (2014). The results corroborate consolidated perceptions on the topic, such as the high dependence on intergovernmental transfers by small municipalities and the greater fiscal effort of larger municipalities, but also bring new information regarding the use of loan instruments (credit operations) and the liquidity level of local governments. Although the exercise was applied for a period in which the country experienced an economic crisis, it was not possible to observe an impact of this event on the indicators, suggesting that this funding pattern captured by the study has a very strong structural element, which is little sensitive to economic or even political (electoral) cycle..

Keywords: municipality; financing; fiscal revenue; urban hierarchy

\section{Kleber Pacheco de Castro ${ }^{a}$}

a Universidade do Estado do Rio de Janeiro (UERJ), Rio de Janeiro, RJ, Brasil

DOI: 10.12957/geouerj.2019.47281

Correpondência: kleberpcastro@gmail.com

Recebido em: 20 set. 2019 Revisado em: 19 out. 2019 Aceito em: 15 dez.2019 


\section{INTRODUÇÃO}

O federalismo fiscal brasileiro é, historicamente, marcado pela alternância de períodos de maior ou menor centralização de recursos, o que ficou conhecido na literatura como movimento de sístole/diástole da federação (VARSANO, 1996; COSSIO, 2002).

O período pós Constituição Federal de 1988, porém, não é caracterizado por esse comportamento variante, sendo marcado por uma clara trajetória de paulatina desconcentração de recursos, especialmente em direção aos governos municipais. Tamanha é a importância dos municípios no atual quadro de federalismo fiscal brasileiro, que autores e estudiosos sobre o tema chamam o federalismo fiscal brasileiro de municipalismo fiscal ou federalismo municipalista (AFONSO E ARAUJO, 2000; CASTRO E AFONSO, 2010; FERNANDES E WILSON, 2013)

A terminologia não se dá por acaso. Há claras evidências empíricas que corroboram essa tese. Bons exemplos são dados por Serra e Afonso (2007) e Castro e Afonso (2010), que destacam, respectivamente, o processo de descentralização de receitas e de despesas (notadamente despesas sociais) no país. No período mais recente, desde o início da última recessão brasileira (meados de 2014), no qual os estados entraram em uma situação de grave crise fiscal, tem-se acentuado esse maior protagonismo das prefeituras, inclusive assumido responsabilidades em áreas que não são formalmente de sua competência, como é o caso da segurança pública.

Conforme se avança o processo de municipalização das políticas públicas no Brasil, torna-se cada vez mais importante e necessário compreender o padrão de financiamento dos municípios. Isso é especialmente relevante quando nos deparamos com um quadro de crise econômica e fiscal, no qual o espaço orçamentário se estreita demasiadamente. Entender de onde vêm os recursos que contribuem para promover a agenda de serviços públicos das cidades e como estes são influenciados pelo ciclo econômico, são aspectos fundamentais para uma boa gestão urbana.

Outro ponto importante, referente ao diagnóstico do financiamento dos governos locais, diz respeito à transparência e publicidade da distribuição de receitas entre entes da mesma esfera de governo. Trata-se de fugir um pouco do discurso comum de analisar a federação brasileira apenas pela ótica vertical, na qual a divisão de receitas entre as três esferas de governo (União, estados e municípios) é percebida de forma genérica, como se houvesse homogeneidade entre os governos que compõem as esferas subnacionais. Sendo o Brasil um país de dimensões continentais, com grande diversidade cultural e socioeconômica, é natural que isso se reflita no plano federativo, especialmente quando tratamos de municípios. O nível de heterogeneidade, nesse caso, é muito elevado. Por isso, tentar analisar a forma de financiamento desse nível de governo a partir 
de uma classificação que fuja ao senso comum (ex: segmentação regional ou populacional), já é de grande valia para discussões políticas como, por exemplo, a reforma tributária e a reforma do pacto federativo.

Poucos trabalhos procuram mapear e analisar os padrões de financiamento das prefeituras brasileiras. Afonso e Araujo (2000) e Santos e Castro (2018) podem ser apontadas como as pesquisas que mais se aproximam dessa ideia, mas com ênfase na carga tributária em sentido amplo, i.e., que engloba não apenas as receitas tributárias próprias, mas também as transferências intergovernamentais auferidas. Nesses artigos, não há discussão sobre formas alternativas de financiamento, como é o caso da tomada de crédito para investimentos (operações de crédito). Além disso, não há preocupação em construir indicadores fiscais que permitam identificar os padrões de financiamento dos distintos grupos de municípios.

Tendo em vista essa aparente lacuna na literatura, esse artigo pretende apresentar uma análise intertemporal do financiamento local a partir da apresentação de indicadores fiscais para grupos de municípios, delimitados pela classificação da "hierarquia de centros urbanos" (IBGE, 2008). O uso dos indicadores em um intervalo de tempo responde à ideia de tentar captar os padrões de financiamento e verificar se houve mudança nesses padrões, tentando correlacionar eventuais movimentos com o comportamento da economia nacional.

Além dessa introdução, esse artigo conta com mais quatro seções: a segunda seção apresentará uma breve contextualização da receita tributária local, respaldada pela literatura prévia no tema; a terceira seção tratará das considerações metodológicas da pesquisa, com apresentação dos indicadores escolhidos, da delimitação dos grupos de análise e da base de dados; a quarta seção cuidará de apresentar e analisar os resultados do exercício aplicado; a quinta seção tecerá considerações finais.

\section{CONTEXTUALIZANDO A RECEITA TRIBUTÁRIA MUNICIPAL}

Antes de se iniciar a execução do exercício proposto, é importante fazer uma breve contextualização da receita tributária municipal, destacando sua evolução recente, sua estrutura e sua distribuição no território nacional.

Assim, destacam-se a seguir algumas características marcantes da tributação e da receita tributária a nível municipal:

1. Houve uma nítida expansão da carga tributária municipal desde 1988 , tanto pela ótica da arrecadação direta, como pela ótica receita disponível. De acordo com dados de Afonso e Castro (2018), a participação municipal no total da carga tributária bruta brasileira passou de 2,7\% em 1988 para 7,4\% 
em 2017, no caso da arrecadação direta, e de 13,3\% em 1988 para 20\% em 2017, no caso da receita disponível.

2. O crescimento da arrecadação direta está relacionado, principalmente, ao fato do ISSQN ter tido um desempenho acima da média dos demais tributos do sistema tributário, fato comprovável a partir de rápida análise dos dados de Afonso e Castro (2018). Isso é explicado por sua base de incidência: o setor de serviços. Tendo em vista que essa atividade tem crescente participação na determinação do PIB de maior parte dos países (MILES, 1993), inclusive o Brasil, o ISSQN acaba se beneficiando em termos de arrecadação. Trata-se do tributo com o maior potencial arrecadatório do atual sistema tributário nacional.

3. A despeito do fato da União ter empregado, a partir da década de 1990, diversas políticas que prejudicaram o volume de recursos transferidos aos municípios via FPM (VARSANO et al., 1998; AFFONSO, 2000), houve uma tendência de aumento da participação dos municípios na receita recolhida pela União desde a Constituição. Segundo, STN (2018) os municípios recebiam 17\% da receita de IR e IPI em 1988 (antes da promulgação da Constituição) e atualmente recebem 24,5\% desses impostos. Outro importante impulso para a receita municipal foi o aumento da participação deste ente na arrecadação do ICMS, passando de $20 \%$ para $25 \%$ na Constituição de 1988 . Soma-se a isso o alargamento da base de incidência do ICMS na mesma carta magna (BREGMAN, 2011). Percebese aí o motivo pelo qual a receita disponível dos municípios também se expandiu significativamente a partir de 1988.

4. Verifica-se uma marcante heterogeneidade da distribuição da carga tributária entre os municípios, com claras diferenças entre localidades de diferentes regiões e de diferentes portes populacionais. Essa percepção de forte dispersão do ônus fiscal a nível municipal é observado não apenas pela ótica mais tradicional da carga tributária, ou seja, como proporção do PIB, mas também, por óticas alternativas, como é o caso da arrecadação per capita (ver Figura 1). As diferenças são evidentes não apenas entre municípios de regiões diferentes, mas também entre municípios da mesma região ou até da mesma UF. Isso é notado até mesmo em estados ricos, como São Paulo e Paraná. 
Figura 1. Mapa da Receita Disponível per capita por Município - 2016 Elaboração própria. Fonte primária: Finbra/STN e Estimativa Populacional/IBGE.

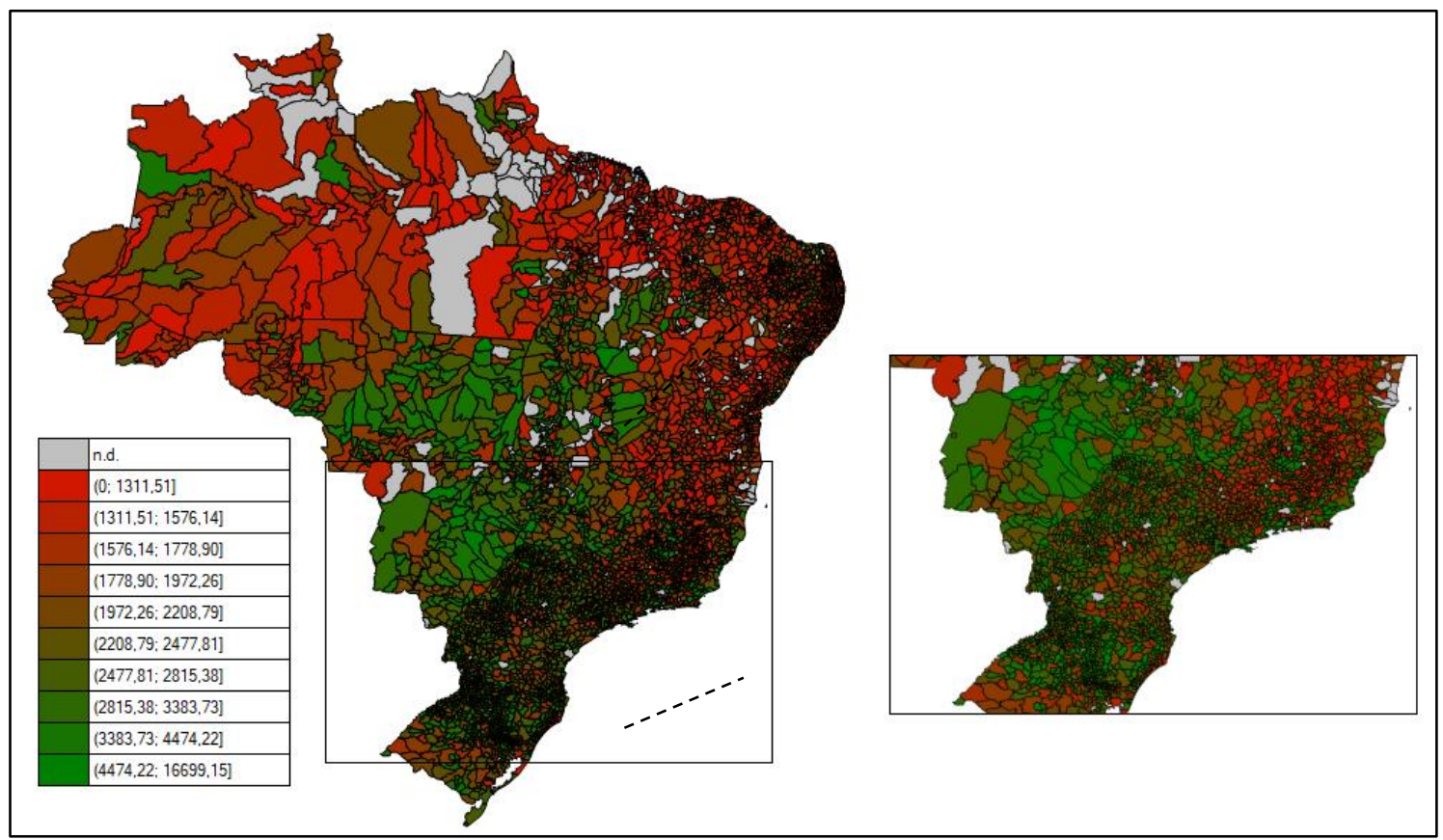

5. De uma forma geral, a carga tributária municipal a partir da concepção de receita própria (arrecadação direta), tende a ser mais elevada nas maiores cidades. Contudo, a carga tributária pela ótica da receita disponível (receita própria mais transferências intergovernamentais) tende a ser maior nas localidades de menor porte. Esse comportamento aparentemente contraditório, pode ser explicado pelo fato das transferências serem fortemente enviesadas em favor de cidades muito pequenas, mais do que compensando a concentração de atividades produtivas nos grandes centros, fato que explica a maior arrecadação própria nestes polos mais dinâmicos (SANTOS E CASTRO, 2018). Outra forma de enxergar esse desbalanceamento horizontal é a partir da constatação de que não há sistema de equalização fiscal no Brasil (CASTRO, 2019).

Partindo-se desse esboço de cenário do financiamento municipal, há uma expectativa de que o exercício a ser aplicado nesse artigo apresente resultados consistentes com tal contexto, quais sejam: existência de grande heterogeneidade na forma de captação de recursos pelas prefeituras, com maior autonomia fiscal nos grandes centros e grande dependência de recursos de outras esferas de governo nos chamados "centros locais". Espera-se ainda que o padrão de obtenção de crédito para financiamento de projetos de investimento também deve se mostrar muito pouco equânime. 


\section{METODOLOGIA}

Indicadores de financiamento municipal

O exercício que pretende ser aplicado nesse artigo consiste basicamente na construção de indicadores fiscais relacionados à dimensão da receita municipal que permitam captar os padrões de financiamento das prefeituras. Para delimitar quais indicadores seriam utilizados no trabalho, recorreu-se a Cialdini e Afonso (2014), que apresentam e defendem a utilização regular de uma série de indicadores fiscais - não apenas relativos ao financiamento - dentro de um contexto de acompanhamento mais rigoroso das contas públicas e do balizamento da gestão fiscal nos municípios. Os autores indicam, não apenas os indicadores, como também apontam quais seriam os "limites" ou "margens" desses indicadores, aos quais os municípios deveriam, idealmente, se enquadrar em uma situação de boa gestão das contas públicas. Cinco indicadores foram selecionados para compor esse artigo, os quais são apresentados a seguir.

\section{Índice de Liquidez}

$$
I L_{i}=\frac{R A_{i}}{D E_{i}}
$$

Relação entre "receita arrecadada total" e "despesas empenhadas". Quando o resultado é maior do que a unidade, diz-se haver liquidez. O índice demonstra que se há cobertura para despesas no curto prazo. É importante ter e manter uma boa liquidez. Por outro lado, uma liquidez muito alta pode indicar disponibilidades excessivas, falta de capacidade de gestão e visão para investimento. Formalmente deve ser apurado pela relação entre o "ativo circulante" e o "passivo circulante". Contudo, a relação apresentada na fórmula é uma boa proxy para o indicador.

\section{$\underline{\text { Índice de Esforço Fiscal Próprio }}$}

$$
I E F P_{i}=\frac{(I S S+I P T U+I T B I+T a x a s)_{i}}{R C L_{i}}
$$

Relação entre os principais tributos municipais (ISS, IPTU, ITBI e taxas) e a "receita corrente líquida". Representa o esforço fiscal local, focado na efetiva receita tributária própria, composta por tributos que exijam diretamente medidas de incremento da arrecadação. Prudencialmente, por uma questão de autonomia, é recomendável que o indicador seja superior a 20\%, inclusive para os municípios de menor porte.

\section{Índice de Dependência de Transferências}

$$
I D T_{i}=\frac{(F P M+\operatorname{CotaICMS}+F U N D E B)_{i}}{R C L_{i}}
$$


Relação entre as principais transferências intergovenamentais obrigatórias auferidas pelos municípios (FPM, Cota-Parte do ICMS e FUNDEB) e a "receita corrente líquida". Representa o grau de dependência do governo local com relação às receitas recolhidas por outras esferas de governo. Prudencialmente, por uma questão de autonomia, é recomendável que o indicador seja inferior a $80 \%$, inclusive para os municípios de menor porte.

\section{Índice da Regra de Ouro}

$$
I R O_{i}=\frac{O C_{i}}{D C_{i}}
$$

Relação entre "operações de crédito" e "despesas de capital executadas ${ }^{1 "}$. Representa uma métrica para identificar se os governos estão se endividando (tomando crédito) para o pagamento de despesas correntes como: pessoal, benefícios sociais, juros da dívida e o custeio da máquina pública. Trata-se de uma exigência legal que o indicador não seja superior à unidade.

\section{Índice de Operações de Crédito}

$$
I O C_{i}=\frac{O C_{i}}{R C L_{i}}
$$

Relação entre "operações de crédito" e "receita corrente líquida". Representa o nível de tomada de crédito vis-à-vis o tamanho do orçamento local, contribuindo para verificar se a prefeitura terá capacidade de honrar seus compromissos financeiros (pagamento da dívida contratada) no futuro. Legalmente, este indicador não pode superar $16 \%$.

\section{Definindo os grupos de municípios}

A delimitação de distintos grupos é fundamental para que o exerício não incorra no equívoco de comparar municípios de perfis muito distintos. Como o Brasil tem 5.570 (cinco mil quinhentos e setenta) localidades, é natural que haja diferenças. Considerando ainda que o Brasil é um país de dimensões continentais, essas diferenças se tornam ainda mais acentuadas. Para se ter ideia, temos municípios que mais se assemelham a um governo estadual - em termos de porte de orçamento e de execução de políticas públicas - do que a um governo local, como é o caso de São Paulo/SP, por exemplo. Ao mesmo tempo, temos municípios que mais se assemelham a um distrito ou um bairro de uma cidade média, situação que pode ser ilustrada por Serra da Saudade/MG, o menor município do Brasil, com pouco mais de 800 (oitocentos) habitantes.

\footnotetext{
1 Executadas = liquidadas e inscritas em restos a pagar não processados.
} 
Nesse caso, optou-se por seguir a classificação das cidades segundo a hierarquia de centros urbanos, que leva "[...] em conta a classificação dos centros de gestão do território, a intensidade de relacionamentos e a dimensão da região de influência de cada centro, bem como as diferenciações regionais", (IBGE, 2008, p.11). Essa classificação faz uma divisão dos municípios em 5 (cinco) grandes grupos: i) metrópoles: principais centros urbanos do País, que caracterizam-se por seu grande porte e por fortes relacionamentos entre si, além de, em geral, possuírem extensa área de influência direta; ii) capital regional: centros que também se relacionam com o estrato superior da rede urbana, mas com capacidade de gestão no nível imediatamente inferior ao das metrópoles, possuem área de influência de âmbito regional, sendo referidas como destino, para um conjunto de atividades, por grande número de municípios; iii) centro sub-regional: centros com atividades de gestão menos complexas, têm área de atuação mais reduzida, e seus relacionamentos com centros externos à sua própria rede dão-se, em geral, apenas com as três metrópoles "nacionais" (São Paulo, Rio de Janeiro e Brasília); iv) centro de zona: cidades de menor porte e com atuação restrita à sua área imediata, exercendo funções de gestão elementares; e v) centro local: cidades cuja centralidade e atuação não extrapolam os limites do seu município, servindo apenas aos seus habitantes, têm população dominantemente inferior a 10 mil habitantes.

Convém fazer uma rápida digressão para explicar uma imputação de classificação hierárquica para uma pequena parte dos municípios, que não estavam contemplados na pesquisa de IBGE (2008). A despeito do fato do Brasil possuir 5.564 (cinco mil quinhentos e sessenta e quatro) municípios à época do levantamento dessa pesquisa, em 2007, a classificação dessas segundo a hierarquia de centros urbanos só englobou 5.274 (cinco mil duzentos e setenta e quatro) localidades. Assim, fez-se necessário imputar a classificação das cidades não incluídas no levantamento original, além dos municípios que foram criados posteriormente. A partir de parâmetros demográficos (população estimada) e econômicos (PIB municipal), os 296 (duzentos e noventa e seis) municípios restantes foram enquadrados em um dos 5 (cinco) grupos definidos originalmente, seguindo uma lógica de aproximação para a média desses grupos. Tal procedimento pouco interfere na análise, haja vista que praticamente todos os municípios de maior influência na hierarquia urbana já estavam classificados em IBGE (2008). Verificou-se que mais de $90 \%$ desses municípios com classificação imputada acabaram sendo enquadrados como "centro local".

\section{Construindo a base de dados}

Todos os dados primários utilizados nesse artigo foram extraídos de fontes oficiais - isto é, de órgãos do governo ou de organismos internacionais que se baseiam suas pesquisas em órgãos do governo. O IBGE e a STN (Secretaria do Tesouro Nacional) foram as principais fontes de informações, a partir das seguintes 
pesquisas: Estimativa Populacional Municipal; PIB Municipal; Regiões de influência das cidades (IBGE, 2008); e Finbra (Finanças do Brasil).

O período de análise foi o mais longo possível, sendo delimitado basicamente pela disponibilidade de dados. Apesar da dificuldade de se consolidar uma base de série temporal longa em nível municipal, dependendo das variáveis utilizadas, foi possível estender essa série para um período de 9 (nove) anos, de 2009 a 2017. O fato de os indicadores propostos poderem ser extraídos exclusivamente de uma fonte (Finbra) facilitou essa consolidação.

Devido ao grande número de municípios existentes no Brasil e à grande heterogeneidade entre eles, é comum que algumas informações neste nível não estejam totalmente disponíveis, ainda que apresentem boas amostras. De qualquer forma, todas as informações obtidas passaram por uma depuração, no sentido de serem excluídos erros crassos (ex: valores nulos, ausência de dados) e possíveis outliers, que se apresentaram em ao menos um indicador, em pelo menos um ano da amostra. Outros testes de consistência ${ }^{2}$ também foram aplicados com o intuito de eliminar o máximo de ruídos da base.

Dadas essas considerações, chegou-se a um painel balanceado com uma amostra de 3.955 (três mil novecentos e cinquenta e cinco) municípios, sendo: i) 3.176 (três mil cento e setenta e seis) centros locais; ii) 483 (quatrocentos e oitenta e três) centros de zona; iii) 203 (duzentos e três) centros sub-regionais; iv) 82 (oitenta e dois) capitais regionais; e v) 11 (onze) metrópoles ${ }^{3}$.

\section{RESULTADOS}

\section{Centro Local}

No primeiro grupo de análise, os resultados médios ${ }^{4}$ dos cinco indicadores de financiamento municipal se portaram dentro do esperado para esse conjunto: i) Índice de Liquidez superior à unidade em todos os anos da série, com leve evolução positiva no intervalo em análise; ii) Índice de Esforço Fiscal Próprio demasiadamente baixo (média geral de aproximadamente $7 \%$ para todo o período), ainda que tenha se observado uma suave melhora do indicador entre 2009 e 2017; iii) Índice de Dependência de Transferências

\footnotetext{
2 Como o produto final do exercício são indicadores relativos (quocientes), foi possível, a partir de dedução lógica eliminar dados errados a partir da simples observação desses. Por exemplo, apesar de ser possível, é extremamente improvável que a soma de ISS, IPTU, ITBI e Taxas seja superior à RCL. Assim, um município que tenha apresentado o IEFP próximo ou superior à unidade seria um candidato à avaliação fina de seus dados, sendo excluído da base caso essa conferência apontasse para a existência de erro de informação.

${ }^{3}$ Brasília foi excluída da amostra por configurar um arranjo político-administrativo diferente dos demais municípios.

4 Optou-se pelo uso da média a partir do fato de que houve rigoroso ajuste e depuração da base de dados, eliminando outliers que poderiam distorcer esses resultados médios. Testes utilizando a mediana foram feitos, obtendo-se resultados gerais muito similares, com os mesmos padrões apontados pela média.
} 
muito elevado (média geral de aproximadamente $75 \%$ para todo o período), apesar de demonstrar uma trajetória de queda ao longo do tempo; iv) Índice da Regra de Ouro quase irrelevante em todo o período, o que é um reflexo de uma certa flexibilidade da regra brasileira ${ }^{5}$ e da pouca aderência desse grupo de municípios na tomada de empréstimo via operações de crédito (apenas 11\% se enquadra nessa situação em 2017); e v) Índice de Operações de Crédito igualmente irrelevante, pelo mesmo motivo apontado anteriormente. A Tabela 1 apresenta um resumo desses resultados.

Tabela 1. Evolução da Média dos Indicadores de Financiamento dos Municípios Classificados como Centro Local - 2009/2017 Elaboração própria. Fonte primária: Finbra/STN.

\begin{tabular}{cccccc}
\hline Ano & IL & IEFP & IDT & IRO & IOC \\
\hline 2009 & 1,068 & 0,067 & 0,764 & 0,040 & 0,004 \\
2010 & 1,041 & 0,070 & 0,759 & 0,035 & 0,004 \\
2011 & 1,076 & 0,069 & 0,770 & 0,032 & 0,004 \\
2012 & 1,036 & 0,070 & 0,742 & 0,034 & 0,005 \\
2013 & 1,082 & 0,073 & 0,759 & 0,022 & 0,002 \\
2014 & 1,027 & 0,075 & 0,739 & 0,024 & 0,003 \\
2015 & 1,052 & 0,074 & 0,751 & 0,030 & 0,003 \\
2016 & 1,085 & 0,068 & 0,749 & 0,049 & 0,005 \\
2017 & 1,082 & 0,072 & 0,741 & 0,031 & 0,002 \\
$2017-2009$ & 0,014 & 0,005 & $-0,023$ & $-0,009$ & $-0,002$ \\
\hline
\end{tabular}

Outra possibilidade de avaliação desses dados pode ser feita a partir dos limites dos indicadores, apontados por Cialdini e Afonso (2014). Relembrando o disposto na seção metodológica, segundo os autores o IL deve ser superior à unidade (mas também não deve ser demasiadamente superior à 1), o IEFP deve ser superior à $20 \%$, o IDT deve ser inferior a $80 \%$, o IRO deve ser inferior à unidade e o ICO deve ser inferior à $16 \%$. Os dois últimos limites são definidos legalmente.

\footnotetext{
5 “[...] o ponto central a se ter em mente é que a maneira como a Regra de Ouro brasileira foi desenhada e operacionalizada faz com que ela se distancie da sua configuração clássica. São duas principais razões para este distanciamento: 1. A regra brasileira admite uma definição muito abrangente de despesas de capital que abre espaço para que seu cumprimento mesmo com endividamento crescendo muito acima dos investimentos públicos. Basta que esta diferença seja compensada pelas demais categorias contabilizadas entre as despesas de capital (por exemplo, via expansão das despesas financeiras do Tesouro Nacional com empréstimos ou com atualização monetária do principal da dívida pública). 2. A regra brasileira não exige necessariamente equilíbrio do orçamento corrente. Sua restrição deve ser mais apropriadamente interpretada como um teto para o déficit corrente que depende diretamente do volume de receitas e despesas financeiras do governo federal. Na medida em que ao longo dos anos, por variados motivos, as receitas e despesas financeiras alcançaram volumes expressivos, o teto para o déficit corrente acabou sendo relativamente elevado. Ademais, boa parte das fontes financeiras está relacionada a relações intra-setor público (por exemplo, entre o Tesouro Nacional e o BNDES ou outros fundos públicos) que geram margem de manobra para que o governo oportunamente as utilize como meio de flexibilizar o teto de déficit corrente. Ou seja, a restrição da Regra de Ouro brasileira estabelece um teto flexível para o déficit corrente (e não necessariamente o seu equilíbrio).", (COURI et al., 2018, p.15-16).
} 
Nesse novo prisma de análise, vale observar a frequência relativa de governos locais que atendem aos limites destacados anteriormente. Isto é, para cada grupo de análise, checar o percentual de municípios que atendem os requisitos de uma boa gestão fiscal a partir dos seus indicadores de financiamento.

O mesmo movimento de melhoria da média dos indicadores entre 2009 e 2017, observado na Tabela 1, também é notado nessa nova análise. Ou seja, a frequência relativa de municípios que se enquadram aos limites apresentou melhora ou estabilidade nesse intervalo, no grupo de municípios classificados como centros locais, como é possível notar na Tabela 2.

Tabela 2. Evolução da Frequência Relativa dos Limites dos Indicadores de Financiamento nos Municípios Classificados como Centro Local - 2009/2017 Elaboração própria. Fonte primária: Finbra/STN.

\begin{tabular}{cccccc}
\hline Ano & IL > 100\% & IEFP $\geq \mathbf{2 0} \%$ & IDT $<\mathbf{8 0 \%}$ & IRO $\leq \mathbf{1 0 0} \%$ & IOC $\leq \mathbf{1 6 \%}$ \\
\hline 2009 & $84,0 \%$ & $1,7 \%$ & $33,1 \%$ & $99,9 \%$ & $99,9 \%$ \\
2010 & $72,4 \%$ & $2,1 \%$ & $35,5 \%$ & $99,8 \%$ & $100,0 \%$ \\
2011 & $87,5 \%$ & $1,7 \%$ & $29,3 \%$ & $99,9 \%$ & $100,0 \%$ \\
2012 & $70,7 \%$ & $1,9 \%$ & $38,0 \%$ & $99,9 \%$ & $100,0 \%$ \\
2013 & $84,9 \%$ & $1,8 \%$ & $32,4 \%$ & $100,0 \%$ & $100,0 \%$ \\
2014 & $70,1 \%$ & $2,1 \%$ & $37,9 \%$ & $100,0 \%$ & $100,0 \%$ \\
2015 & $80,5 \%$ & $2,1 \%$ & $35,7 \%$ & $99,9 \%$ & $100,0 \%$ \\
2016 & $89,5 \%$ & $1,5 \%$ & $39,0 \%$ & $99,9 \%$ & $100,0 \%$ \\
2017 & $86,3 \%$ & $2,0 \%$ & $40,4 \%$ & $99,9 \%$ & $100,0 \%$ \\
$2017-2009$ & $2,3 \%$ & $0,3 \%$ & $7,4 \%$ & $0,0 \%$ & $0,1 \%$ \\
\hline
\end{tabular}

Inicialmente, vale destacar que os indicadores relativos à operação de crédito estiveram, quase sempre, em $100 \%$, descartando eventuais problemas desse grupo com o cumprimento dos limites legais relativos a esse tipo de empréstimo. $\mathrm{O}$ fato de poucos municípios do grupo tomarem crédito contribui para esse resultado, haja vista que $89 \%$ dos municípios do grupo sequer têm a possibilidade de violar esses limites, pois não tomaram crédito.

O ponto mais relevante apresentado pela Tabela 2 diz respeito ao sensível aumento de municípios com Índice de Dependência de Transferências inferior a 80\%: apesar desse percentual ter oscilado no intervalo de tempo em questão, aproximadamente $40 \%$ do grupo se enquadrou nessa situação em 2017 , enquanto em 2009 esse percentual era de 33\%. O resultado é consistente com a queda do IDT médio apresentado na Tabela 1.

Como não é notado um crescimento similar na frequência de localidades com Índice de Esforço Fiscal Próprio superior à $20 \%$, é razoável deduzir que a queda do IDT (médio e frequência) pode estar relacionada a 
um maior peso de receitas não tributária (como as receitas patrimoniais, por exemplo) ou ainda de tributos ou transferências que não são captados pelos indicadores, haja vista que, tanto o IEFP, como o IDT, se atêm apenas às principais rubricas de receita própria (ISS, IPTU, ITBI e Taxas) e de transferências (FPM, Cota-Parte do ICMS e FUNDEB).

A despeito da evolução suavemente positiva, é importante observar a baixíssima frequência de municípios com IEFP superior a 20\%: na média geral de todo o intervalo do tempo, nem $2 \%$ dos municípios desse grupo atingem tal patamar. Esse padrão é consistente com a tese de que os municípios de menor porte dependem demasiadamente de transferências de impostos de outras esferas de governo (GOMES E MACDOWELL, 2000).

Já o Índice de Liquidez, apresentou uma frequência média relativamente alta, mas com uma trajetória pouco clara, muito oscilante. De 2014 em diante - durante a crise econômica - o resultado melhorou de forma expressiva, não sendo possível traçar qualquer tipo de correlação desse com a maior restrição fiscal do período. Ainda que tenha havido algum tipo de controle no volume de despesas empenhadas, no orçamento público brasileiro, os gastos são mais rígidos e menos sensíveis ao ciclo econômico do que as receitas - o que deveria resultar em uma piora (não verificada) do IL.

\section{Centro de Zona}

No segundo grupo de análise, tal qual se verificou no primeiro grupo, os resultados médios dos cinco indicadores de financiamento municipal se portaram dentro do esperado para esse conjunto: i) Índice de Liquidez superior à unidade em todos os anos da série, com leve evolução positiva no intervalo em análise; ii) Índice de Esforço Fiscal Próprio baixo (média geral de aproximadamente 13,4\% para todo o período), mas em patamar superior ao que fora observado no grupo dos centros locais; iii) Índice de Dependência de Transferências elevado (média geral de aproximadamente 62\% para todo o período), apesar de demonstrar uma trajetória de queda ao longo do tempo e de estar abaixo da dependência evidenciada pelos centros locais; iv) Índice da Regra de Ouro baixo em todo o período (ainda que acima da média do grupo anterior), fruto da já apontada flexibilidade da regra brasileira e da pouca aderência desse grupo de municípios na tomada de empréstimo via operações de crédito (apenas 25\% se enquadra nessa situação em 2017); e v) Índice de Operações de Crédito se mostra praticamente irrelevante, pelo mesmo motivo apontado anteriormente. A Tabela 3 apresenta um resumo desses resultados. 
Tabela 3. Evolução da Média dos Indicadores de Financiamento dos Municípios Classificados como Centro de Zona 2009/2017 Elaboração própria. Fonte primária: Finbra/STN.

\begin{tabular}{cccccc}
\hline Ano & IL & IEFP & IDT & IRO & IOC \\
\hline 2009 & 1,069 & 0,126 & 0,644 & 0,059 & 0,006 \\
2010 & 1,063 & 0,132 & 0,639 & 0,047 & 0,005 \\
2011 & 1,076 & 0,134 & 0,641 & 0,042 & 0,005 \\
2012 & 1,047 & 0,135 & 0,608 & 0,061 & 0,008 \\
2013 & 1,074 & 0,138 & 0,630 & 0,043 & 0,005 \\
2014 & 1,017 & 0,141 & 0,613 & 0,032 & 0,004 \\
2015 & 1,032 & 0,138 & 0,613 & 0,056 & 0,005 \\
2016 & 1,078 & 0,129 & 0,600 & 0,070 & 0,006 \\
2017 & 1,078 & 0,134 & 0,597 & 0,063 & 0,004 \\
$2017-2009$ & 0,009 & 0,008 & $-0,047$ & 0,004 & $-0,002$ \\
\hline
\end{tabular}

Mudando o foco de análise da média dos indicadores para a verificação da frequência de municípios dentro dos limites dos indicadores, observa-se uma tendência de aumento ou de estabilidade do número relativo de municípios em todas as situações, da mesma forma que se deu no grupo de municípios classificados como centro local. Isso pode ser checado na Tabela 4.

Tabela 4. Evolução da Frequência Relativa dos Limites dos Indicadores de Financiamento nos Municípios Classificados como Centro de Zona - 2009/2017 Elaboração própria. Fonte primária: Finbra/STN.

\begin{tabular}{cccccc}
\hline Ano & IL > 100\% & IEFP $\geq \mathbf{2 0 \%}$ & IDT $<\mathbf{8 0 \%}$ & IRO $\leq \mathbf{1 0 0} \%$ & IOC $\leq \mathbf{1 6 \%}$ \\
\hline 2009 & $80,1 \%$ & $5,6 \%$ & $83,9 \%$ & $99,6 \%$ & $99,6 \%$ \\
2010 & $72,3 \%$ & $6,4 \%$ & $84,3 \%$ & $100,0 \%$ & $100,0 \%$ \\
2011 & $85,5 \%$ & $5,8 \%$ & $80,5 \%$ & $100,0 \%$ & $100,0 \%$ \\
2012 & $68,9 \%$ & $5,8 \%$ & $87,0 \%$ & $100,0 \%$ & $100,0 \%$ \\
2013 & $84,7 \%$ & $6,2 \%$ & $85,3 \%$ & $100,0 \%$ & $100,0 \%$ \\
2014 & $64,2 \%$ & $6,4 \%$ & $87,2 \%$ & $100,0 \%$ & $100,0 \%$ \\
2015 & $72,5 \%$ & $6,8 \%$ & $87,8 \%$ & $99,8 \%$ & $100,0 \%$ \\
2016 & $85,1 \%$ & $6,4 \%$ & $87,6 \%$ & $99,8 \%$ & $100,0 \%$ \\
2017 & $82,2 \%$ & $6,6 \%$ & $88,8 \%$ & $99,8 \%$ & $100,0 \%$ \\
$2017-2009$ & $2,1 \%$ & $1,0 \%$ & $5,0 \%$ & $0,2 \%$ & $0,4 \%$ \\
\hline
\end{tabular}

Inicialmente, vale destacar que os indicadores relativos à operação de crédito estiveram, quase sempre, em $100 \%$, descartando eventuais problemas desse grupo com o cumprimento dos limites legais relativos a esse tipo de empréstimo. O fato de poucos municípios do grupo tomarem crédito contribui para esse resultado, haja vista que $75 \%$ dos municípios do grupo sequer têm a possibilidade de violar esses limites, pois não tomaram crédito. 
Assim como no grupo de municípios analisado anteriormente, o ponto o aumento de municípios com Índice de Dependência de Transferências inferior a 80\% é o destaque na Tabela 4: aproximadamente $89 \%$ do grupo se enquadrou nessa situação em 2017, enquanto em 2009 esse percentual era de 84\%. Esse patamar elevado chama a atenção, pois é mais do que o dobro da frequência verificada no grupo de centros locais, o nos faz perceber como a subida na hierarquia urbana é determinante para apontar a origem do financiamento dos municípios.

Também se observa uma significativa melhora relativa na frequência de localidades com Índice de Esforço Fiscal Próprio superior à 20\%, o que é consistente com ao aumento do número de municípios com IDT inferior a $80 \%$. De qualquer forma, a despeito da evolução suavemente positiva, é importante observar que a frequência de municípios com IEFP superior a 20\% ainda é baixa: a média geral de todo o intervalo do tempo é ligeiramente superior a $6 \%$ dos municípios. Mais uma vez, verifica-se um padrão de municípios pequenos altamente dependentes de recursos de outros níveis de governo (GOMES E MACDOWELL, 2000), uma vez que os municípios classificados como centros de zona ainda apresentam um perfil de baixo contingente populacional e baixo dinamismo econômico.

Já o Índice de Liquidez, apresentou uma frequência média relativamente alta, mas sem padrão definido, com comportamento muito volátil ao longo do período em questão, sendo contraproducente tentar estabelecer alguma relação desse resultado com a conjuntura econômica e fiscal.

\section{Centro de Sub-regional}

No terceiro grupo de análise, novamente, os resultados médios dos cinco indicadores de financiamento municipal se portaram dentro do esperado para esse conjunto: i) Índice de Liquidez superior à unidade em todos os anos da série, com leve evolução positiva no intervalo em análise; ii) Índice de Esforço Fiscal Próprio médio (média geral de aproximadamente 17,7\% para todo o período), mas em patamar superior ao que fora observado nos grupos dos centros locais e dos centros de zona; iii) Índice de Dependência de Transferências médio (média geral de aproximadamente 53,6\% para todo o período), inferior ao resultado dos dois grupos analisados anteriormente e que apresenta uma trajetória de queda ao longo do tempo; iv) Índice da Regra de Ouro baixo em todo o período (ainda que acima da média dos grupos anteriores), fruto da já apontada flexibilidade da regra brasileira; e v) Índice de Operações de Crédito se mostra praticamente irrelevante, pelo mesmo motivo apontado anteriormente. A Tabela 5 apresenta um resumo desses resultados. 
Tabela 5. Evolução da Média dos Indicadores de Financiamento dos Municípios Classificados como Centro Sub-regional 2009/2017 Elaboração própria. Fonte primária: Finbra/STN.

\begin{tabular}{cccccc}
\hline Ano & IL & IEFP & IDT & IRO & IOC \\
\hline 2009 & 1,049 & 0,165 & 0,556 & 0,063 & 0,007 \\
2010 & 1,050 & 0,170 & 0,555 & 0,069 & 0,007 \\
2011 & 1,060 & 0,171 & 0,556 & 0,057 & 0,006 \\
2012 & 1,032 & 0,176 & 0,534 & 0,072 & 0,009 \\
2013 & 1,060 & 0,183 & 0,548 & 0,051 & 0,005 \\
2014 & 1,026 & 0,184 & 0,524 & 0,058 & 0,006 \\
2015 & 1,025 & 0,182 & 0,524 & 0,087 & 0,008 \\
2016 & 1,055 & 0,176 & 0,521 & 0,104 & 0,009 \\
2017 & 1,074 & 0,185 & 0,510 & 0,075 & 0,005 \\
$2017-2009$ & 0,025 & 0,020 & $-0,046$ & 0,013 & $-0,002$ \\
\hline
\end{tabular}

A avaliação alternativa, baseada na incidência de localidades que cumprem os limites representativos de uma boa gestão fiscal (Tabela 6), aponta para uma tendência de aumento ou de estabilidade do número relativo de municípios em todas as situações, da mesma forma que se deu nos dois grupos anteriores.

Tabela 6. Evolução da Frequência Relativa dos Limites dos Indicadores de Financiamento nos Municípios Classificados como Centro Sub-regional - 2009/2017 Elaboração própria. Fonte primária: Finbra/STN.

\begin{tabular}{cccccc}
\hline Ano & IL $>\mathbf{~ 1 0 0 \%}$ & IEFP $\geq \mathbf{2 0} \%$ & IDT $<\mathbf{8 0 \%}$ & IRO $\leq \mathbf{1 0 0} \%$ & IOC $\leq \mathbf{1 6 \%}$ \\
\hline 2009 & $77,8 \%$ & $12,3 \%$ & $97,5 \%$ & $100,0 \%$ & $100,0 \%$ \\
2010 & $75,4 \%$ & $15,3 \%$ & $100,0 \%$ & $99,5 \%$ & $100,0 \%$ \\
2011 & $82,8 \%$ & $16,3 \%$ & $97,5 \%$ & $100,0 \%$ & $100,0 \%$ \\
2012 & $72,9 \%$ & $16,7 \%$ & $99,5 \%$ & $100,0 \%$ & $100,0 \%$ \\
2013 & $80,8 \%$ & $17,7 \%$ & $99,5 \%$ & $100,0 \%$ & $100,0 \%$ \\
2014 & $68,0 \%$ & $18,7 \%$ & $99,5 \%$ & $100,0 \%$ & $100,0 \%$ \\
2015 & $67,5 \%$ & $19,7 \%$ & $99,5 \%$ & $100,0 \%$ & $100,0 \%$ \\
2016 & $77,3 \%$ & $17,7 \%$ & $98,5 \%$ & $99,5 \%$ & $100,0 \%$ \\
2017 & $82,8 \%$ & $22,7 \%$ & $99,5 \%$ & $99,5 \%$ & $100,0 \%$ \\
$2017-2009$ & $4,9 \%$ & $10,3 \%$ & $2,0 \%$ & $-0,5 \%$ & $0,0 \%$ \\
\hline
\end{tabular}

Inicialmente, vale destacar que os indicadores relativos à operação de crédito estiveram, quase sempre, em $100 \%$, descartando eventuais problemas desse grupo com o cumprimento dos limites legais relativos a esse tipo de empréstimo. Nesse caso, aproximadamente $44 \%$ dos municípios realizaram operação de crédito no último ano da série. $O$ fato de praticamente a totalidade dos governos não ter violado os limites relacionados à operação de crédito está mais relacionado ao baixo rigor dessas regras, como já apontado anteriormente (COURI et al., 2018). 
O ponto que chama mais atenção na Tabela 6 é o fato que quase dobrou o percentual de municípios desse grupo com Índice de Esforço Fiscal Próprio superior à 20\%, passando de 12\% para 23\% no intervalo de tempo em análise. Percebe-se também que esse grupo possui uma frequência média bem superior aos grupos anteriores nesse quesito.

Outro indício de que o padrão de financiamento muda conforme o porte da cidade e sua posição na hierarquia urbana é dado pelo percentual de municípios com Índice de Dependência de Transferências inferior a $80 \%$, que fica próximo de $100 \%$ nesse grupo - algo não observável nos dois grupos anteriores. Como essa frequência ficou próxima de $100 \%$ em todos os anos, praticamente não houve crescimento nesse caso.

O caso da frequência dos municípios com o Índice de Liquidez superior à unidade é muito semelhante aos casos anteriores: elevado percentual de municípios atende a esse quesito (76\% na média geral do período), grande volatilidade ao longo do tempo e ausência de correlação com o ciclo econômico.

\section{Capital Regional}

No quarto grupo de análise, os resultados médios dos cinco indicadores de financiamento municipal se portaram dentro do esperado para esse conjunto: i) Índice de Liquidez muito próximo à unidade em todos os anos da série, apesar desse ter ficado abaixo de um em alguns períodos; ii) Índice de Esforço Fiscal Próprio médio (média geral de aproximadamente 22,3\% para todo o período), mas em patamar superior ao que fora observado nos grupos anteriores; iii) Índice de Dependência de Transferências baixo para padrão municipal (média geral de aproximadamente $42,4 \%$ para todo o período), resultado bem inferior ao dos grupos analisados anteriormente e que apresenta uma trajetória de queda ao longo do tempo; iv) Índice da Regra de Ouro médio-baixo em todo o período (mas bem acima dos grupos anteriores), fruto da já apontada flexibilidade da regra brasileira; e v) Índice de Operações de Crédito se mostra praticamente irrelevante, pelo mesmo motivo apontado anteriormente. A Tabela 7 apresenta um resumo desses resultados.

Tabela 7. Evolução da Média dos Indicadores de Financiamento dos Municípios Classificados como Capital Regional 2009/2017, Elaboração própria. Fonte primária: Finbra/STN.

\begin{tabular}{cccccc}
\hline Ano & IL & IEFP & IDT & IRO & IOC \\
\hline 2009 & 1,009 & 0,208 & 0,441 & 0,132 & 0,014 \\
2010 & 0,999 & 0,214 & 0,438 & 0,106 & 0,012 \\
2011 & 1,006 & 0,218 & 0,440 & 0,127 & 0,014 \\
2012 & 1,013 & 0,218 & 0,425 & 0,117 & 0,013 \\
2013 & 1,018 & 0,230 & 0,442 & 0,075 & 0,008 \\
2014 & 0,995 & 0,230 & 0,415 & 0,102 & 0,010 \\
2015 & 0,977 & 0,230 & 0,410 & 0,152 & 0,015 \\
2016 & 0,977 & 0,226 & 0,407 & 0,170 & 0,017 \\
2017 & 1,019 & 0,234 & 0,403 & 0,180 & 0,013 \\
$2017-2009$ & 0,010 & 0,026 & $-0,038$ & 0,048 & $-0,001$ \\
\hline
\end{tabular}


Já na apresentação dos resultados a partir da frequência de governos locais que cumprem os limites pré-estabelecidos para os indicadores, disponível na Tabela 8, observa-se uma tendência de aumento ou de estabilidade do número relativo de municípios em todas as situações, da mesma forma que se deu nos grupos anteriores.

Tabela 8. Evolução da Frequência Relativa dos Limites dos Indicadores de Financiamento nos Municípios Classificados como Capital Regional - 2009/2017 Elaboração própria. Fonte primária: Finbra/STN

\begin{tabular}{cccccc}
\hline Ano & IL $>\mathbf{~ 1 0 0 \%}$ & IEFP $\geq \mathbf{2 0 \%}$ & IDT $<\mathbf{8 0 \%}$ & IRO $\leq \mathbf{1 0 0 \%}$ & IOC $\leq \mathbf{1 6 \%}$ \\
\hline 2009 & $63,4 \%$ & $37,8 \%$ & $98,8 \%$ & $98,8 \%$ & $100,0 \%$ \\
2010 & $57,3 \%$ & $45,1 \%$ & $100,0 \%$ & $100,0 \%$ & $100,0 \%$ \\
2011 & $65,9 \%$ & $42,7 \%$ & $100,0 \%$ & $100,0 \%$ & $100,0 \%$ \\
2012 & $54,9 \%$ & $40,2 \%$ & $100,0 \%$ & $100,0 \%$ & $100,0 \%$ \\
2013 & $69,5 \%$ & $46,3 \%$ & $100,0 \%$ & $100,0 \%$ & $100,0 \%$ \\
2014 & $56,1 \%$ & $50,0 \%$ & $100,0 \%$ & $100,0 \%$ & $100,0 \%$ \\
2015 & $39,0 \%$ & $50,0 \%$ & $100,0 \%$ & $100,0 \%$ & $100,0 \%$ \\
2016 & $48,8 \%$ & $46,3 \%$ & $98,8 \%$ & $100,0 \%$ & $100,0 \%$ \\
2017 & $63,4 \%$ & $53,7 \%$ & $100,0 \%$ & $100,0 \%$ & $100,0 \%$ \\
$2017-2009$ & $0,0 \%$ & $15,9 \%$ & $1,2 \%$ & $1,2 \%$ & $0,0 \%$ \\
\hline
\end{tabular}

Os indicadores relativos à operação de crédito estiveram, quase sempre, em 100\%, descartando eventuais problemas desse grupo com o cumprimento dos limites legais relativos a esse tipo de empréstimo. Nesse caso, aproximadamente $73 \%$ dos municípios realizaram operação de crédito no último ano da série. 0 fato de praticamente a totalidade dos governos não ter violado os limites relacionados à operação de crédito no período em análise está relacionado ao baixo rigor dessas regras no caso brasileiro (COURI et al., 2018).

Novamente, assim como verificado no grupo dos centros sub-regionais, o ponto que chama mais atenção na Tabela 8 é o fato que houve um aumento muito significativo do percentual de municípios com Índice de Esforço Fiscal Próprio superior à 20\%, passando de 38\% para 54\% entre 2009 e 2017. Na média geral desse grupo, quase $46 \%$ das cidades atendem a esse quesito, frequência muito superior à dos grupos anteriores.

Outro indício de que o padrão de financiamento muda conforme o porte da cidade e sua posição na hierarquia urbana é dado pelo percentual de municípios com Índice de Dependência de Transferências inferior a $80 \%$, que fica próximo de $100 \%$ nesse grupo - algo só observável a partir do grupo de cidades classificadas como centro sub-regional. 
A frequência dos municípios com o Índice de Liquidez superior à unidade nesse grupo é inferior à dos demais grupos, atingindo apenas $58 \%$ na média do intervalo. Assim como nos outros casos, também se verifica grande volatilidade da frequência ao longo do tempo nesse caso. A partir daqui, começa a ficar nítido que esse indicador é influenciado negativamente com relação à posição do município na hierarquia urbana - ou seja, municípios maiores aparentam ter um maior problema com caixa para compromissos de curto prazo.

\section{Metrópole}

No quinto e último grupo de análise, os resultados médios dos cinco indicadores de financiamento municipal se portaram dentro do esperado para esse conjunto: i) Índice de Liquidez inferior à unidade em todos os anos, corroborando a tese de menor liquidez nos municípios de maior porte, e com leve trajetória descendente; ii) Índice de Esforço Fiscal Próprio alto (média geral de aproximadamente 39\% para todo o período), superando todos os demais grupos analisados; iii) Índice de Dependência de Transferências baixo (média geral de aproximadamente 29,3\% para todo o período), sendo a menor média entre todos os grupos, abaixo inclusive do seu próprio IEFP; iv) Índice da Regra de Ouro de nível intermediário e com tendência crescente no período, mas muito distante do limite de $100 \%$, o que é resultado flexibilidade da regra brasileira; e v) Índice de Operações de Crédito se mostra praticamente irrelevante, pelo mesmo motivo apontado anteriormente. A Tabela 9 apresenta um resumo desses resultados.

Tabela 9. Evolução da Média dos Indicadores de Financiamento dos Municípios Classificados como Metrópole - 2009/2017 Elaboração própria. Fonte primária: Finbra/STN.

\begin{tabular}{cccccc}
\hline Ano & IL & IEFP & IDT & IRO & IOC \\
\hline 2009 & 0,980 & 0,371 & 0,312 & 0,091 & 0,009 \\
2010 & 0,972 & 0,382 & 0,311 & 0,161 & 0,022 \\
2011 & 0,950 & 0,385 & 0,307 & 0,171 & 0,026 \\
2012 & 0,937 & 0,397 & 0,297 & 0,133 & 0,019 \\
2013 & 0,934 & 0,397 & 0,306 & 0,180 & 0,028 \\
2014 & 0,919 & 0,404 & 0,289 & 0,195 & 0,029 \\
2015 & 0,939 & 0,388 & 0,271 & 0,177 & 0,026 \\
2016 & 0,924 & 0,390 & 0,273 & 0,273 & 0,034 \\
2017 & 0,945 & 0,396 & 0,272 & 0,175 & 0,014 \\
$2017-2009$ & $-0,035$ & 0,026 & $-0,040$ & 0,084 & 0,005 \\
\hline
\end{tabular}

Seguindo com a avaliação dos indicadores desse grupo, muda-se o foco para a frequência de localidades que atendem aos limites de uma gestão fiscal salutar. Nesse caso, apresentado na Tabela 10, observa-se uma 
tendência de aumento ou de estabilidade do número relativo de municípios em todas as situações, da mesma forma que se deu nos grupos anteriores.

Tabela 10. Evolução da Frequência Relativa dos Limites dos Indicadores de Financiamento nos Municípios Classificados como Metrópole - 2009/2017 Elaboração própria. Fonte primária: Finbra/STN.

\begin{tabular}{cccccc}
\hline Ano & IL > 100\% & IEFP $\geq \mathbf{2 0} \%$ & IDT $<\mathbf{8 0 \%}$ & IRO $\leq \mathbf{1 0 0} \%$ & IOC $\leq \mathbf{1 6 \%}$ \\
\hline 2009 & $36,4 \%$ & $81,8 \%$ & $100,0 \%$ & $100,0 \%$ & $100,0 \%$ \\
2010 & $45,5 \%$ & $81,8 \%$ & $100,0 \%$ & $100,0 \%$ & $100,0 \%$ \\
2011 & $54,5 \%$ & $90,9 \%$ & $100,0 \%$ & $100,0 \%$ & $100,0 \%$ \\
2012 & $36,4 \%$ & $90,9 \%$ & $100,0 \%$ & $100,0 \%$ & $100,0 \%$ \\
2013 & $27,3 \%$ & $100,0 \%$ & $100,0 \%$ & $100,0 \%$ & $100,0 \%$ \\
2014 & $27,3 \%$ & $100,0 \%$ & $100,0 \%$ & $100,0 \%$ & $100,0 \%$ \\
2015 & $18,2 \%$ & $90,9 \%$ & $100,0 \%$ & $100,0 \%$ & $100,0 \%$ \\
2016 & $45,5 \%$ & $100,0 \%$ & $100,0 \%$ & $100,0 \%$ & $100,0 \%$ \\
2017 & $45,5 \%$ & $100,0 \%$ & $100,0 \%$ & $100,0 \%$ & $100,0 \%$ \\
$2017-2009$ & $9,1 \%$ & $18,2 \%$ & $0,0 \%$ & $0,0 \%$ & $0,0 \%$ \\
\hline
\end{tabular}

Os indicadores relativos à operação de crédito estiveram, quase sempre, em 100\%, descartando eventuais problemas desse grupo com o cumprimento dos limites legais relativos a esse tipo de empréstimo. Nesse caso, todos os municípios realizaram operação de crédito no último ano da série. Nenhum governo violou os limites relacionados à operação de crédito no período em análise, o que deve estar relacionado ao baixo rigor dessas regras no caso brasileiro (COURI et al., 2018).

Novamente, assim como verificado no grupo dos centros sub-regionais e capitais regionais, o ponto que chama mais atenção na Tabela 10 é o fato que houve um aumento muito significativo do percentual de municípios com Índice de Esforço Fiscal Próprio superior à 20\%, passando de 82\% para $100 \%$ entre 2009 e 2017, marcando o fato de que as metrópoles acabam dependendo mais de seus esforços próprios do que das outras esferas para a obtenção de receita fiscal. Isso é confirmado pela frequência relativa de localidades com Índice de Dependência de Transferências inferior a 80\%, que foi sempre de $100 \%$.

A questão levantada anteriormente sobre a menor disponibilidade relativa de caixa para fazer frente a gastos de curto prazo nas cidades maiores fica bastante evidente aqui, quando se observa que, na média geral do período, apenas $37 \%$ dos municípios do grupo atenderam ao limite do Índice de Liquidez superior à unidade. No ano de 2015, especificamente, essa frequência foi de apenas $18 \%$, o que pode ser um indicador de impacto da crise econômica sobre esse grupo de municípios. Como se trata de um indicador que tem sem seu denominador as despesas empenhadas, é possível que tenha havido maior pressão de gasto a partir de 
2014 sobre essas cidades, que prestam serviços por uma parcela significativa da população. Isso, inclusive, deve ajudar a explicar a piora na média do IL entre 2009 e 2017.

\section{Há padrão no financiamento municipal?}

Se os resultados apresentados anteriormente não permitem traçar com clareza a influência do ciclo econômico (bem como da crise econômica e fiscal vivenciada no país desde 2014) e do ciclo eleitoral sobre o padrão de financiamento municipal, eles permitem observar com muita clareza as diferenças entre os grupos de análise, corroborando evidências apontadas pela literatura prévia.

A figura 2 apresenta a média geral de cada um dos cinco grupos de municípios para cada um dos cinco indicadores de financiamento aqui aplicados.

Figura 2. Média Geral dos Indicadores de Financiamentos dos Municípios por Classificação Hierárquica - 2009/2017 Elaboração própria. Fonte primária: Finbra/STN.

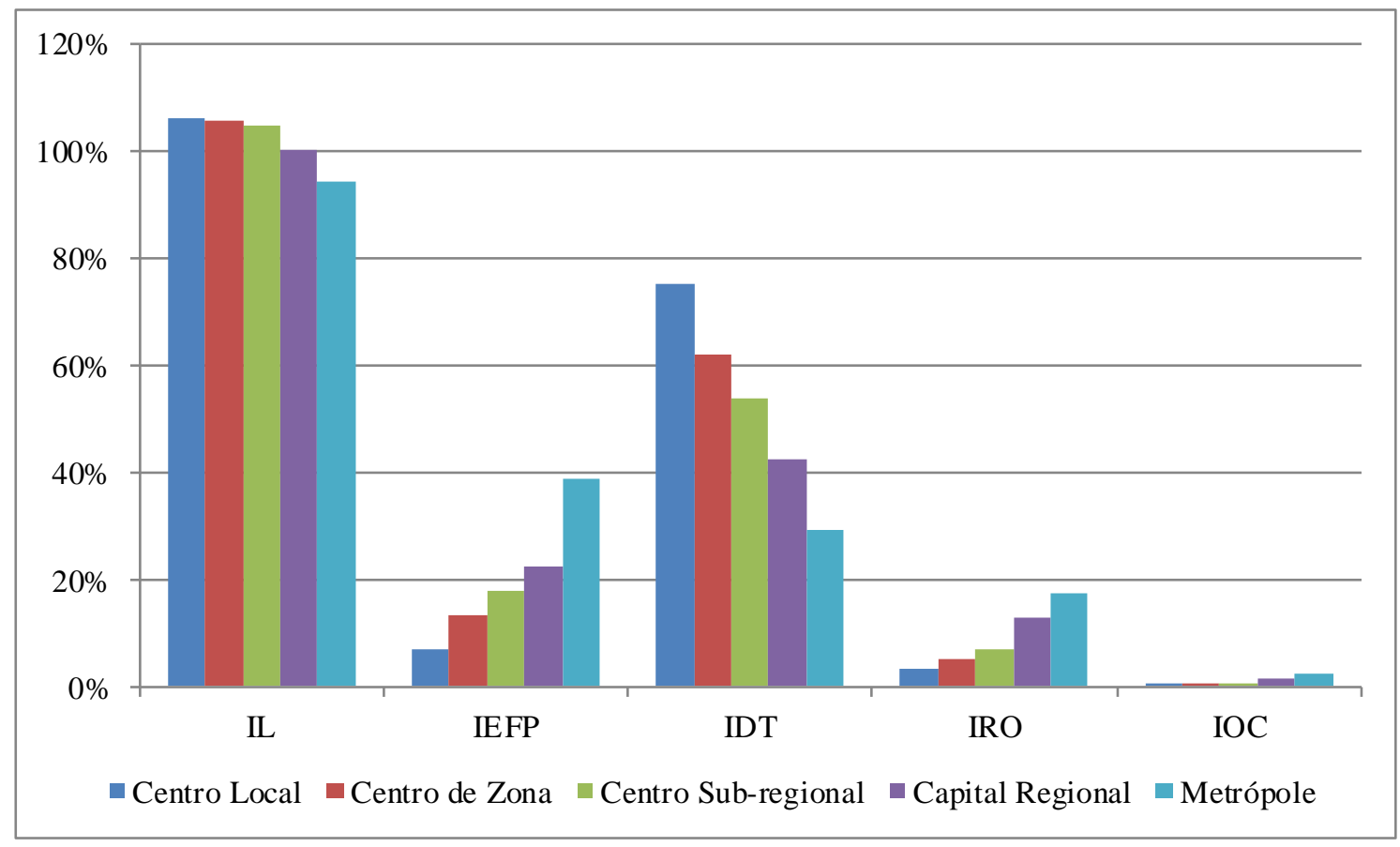

A análise visual do gráfico deixa muito evidente o comportamento dos indicadores conforme se avança na hierarquia de centros urbanos. As conclusões gerais são elencadas a seguir: 
1. Observa-se que o Índice de Liquidez tende a ser mais elevado em pequenos municípios, apresentando resultado médio inferior à unidade apenas nas metrópoles. O IL, formalmente, é uma representação da "[...] existência de recursos prontamente utilizáveis e não vinculados a determinados destinos para fazer frente às obrigações financeiras de curto prazo.", (PELLEGRINI, 2017, p.2). Ocorre que os municípios de maior porte tendem a apresentar um perfil de endividamento mais elevado que os de menor porte, o que pode ser o fato determinante para explicar a relação negativa do IL com o nível hierárquico municipal. $O$ endividamento também implica em maior comprometimento do orçamento com despesas financeiras (relacionadas à dívida), o que proporciona maior nível de despesa empenhada para essas localidades. Além disso, a pressão relativa por despesas nos grandes centros urbanos é maior do que nas pequenas cidades, não apenas pelo contingente populacional, como pelo tipo de problema com que se defronta, usualmente mais complexo do que em localidades menores.

2. O Índice de Esforço Fiscal Próprio se comporta de forma crescente com a hierarquia urbana, o que é um resultado dentro do esperado. A primeira explicação para tal comportamento é o fato de que as atividades de serviços (base para a arrecadação do ISS) serem concentradas nos grandes centros urbanos, devido às economias de aglomeração (MARSHALL, 1996). Consequentemente, pode-se deduzir que o valor imobiliário (base para a arrecadação do IPTU), bem como o dinamismo do mercado imobiliário (base para a arrecadação de ITBI), tende a ser mais elevado nessas cidades. Além disso, o baixo volume de transferências recebidos por esses centros frente a suas necessidades, forçou muito deles a modernizar suas administrações tributárias e intensificar atividades de cobrança e fiscalização. Movimento oposto se deu nas cidades de menor porte: com recursos relativamente mais abundantes das transferências, verifica-se regularmente uma "preguiça fiscal" nessas localidades (TRISTÃO, 2003), que é potencializada pela fraca base de arrecadação.

3. De forma complementar ao item anterior, o Índice de Dependência de Transferências tende a ser mais acentuado nos municípios do início da hierarquia urbana. As explicações são muito similares às anteriores, mas vale enfatizar o viés de distribuição dos recursos do FPM em favor de municípios com população muito baixa (CASTRO E LIMA, 2017) e a partilha da Cota-Parte do ICMS, não guiada por fatores redistributivos, como a população, mas por fatores devolutivos, como o valor adicionado.

4. Ainda com relação ao IDT, percebe-se uma tendência de diminuição desse indicador ao longo do tempo em todos os agrupamentos de municípios. Uma hipótese aventada para explicar isso, além do aumento do IEFP, é a elevação das transferências de propósito específico (vinculadas), especialmente as transferências do SUS. Essa hipótese - formulada a partir da evidência do aumento da participação das transferências da União aos governos subnacionais, em detrimento do gasto federal direto, ao longo das década de 1990 e 2000 (PIOLA, 2017) - é verificada apenas para os três primeiros grupos 
(centro local, centro de zona e centro sub-regional). Para as capitais regionais e metrópoles, isso não se aplica. A figura 3 mostra esse comportamento.

Figura 3. Transferências do SUS como Proporção da Receita Corrente Líquida nos Municípios por Classificação Hierárquica 2009/2017 Elaboração própria. Fonte primária: Finbra/STN e Siops/Datasus.

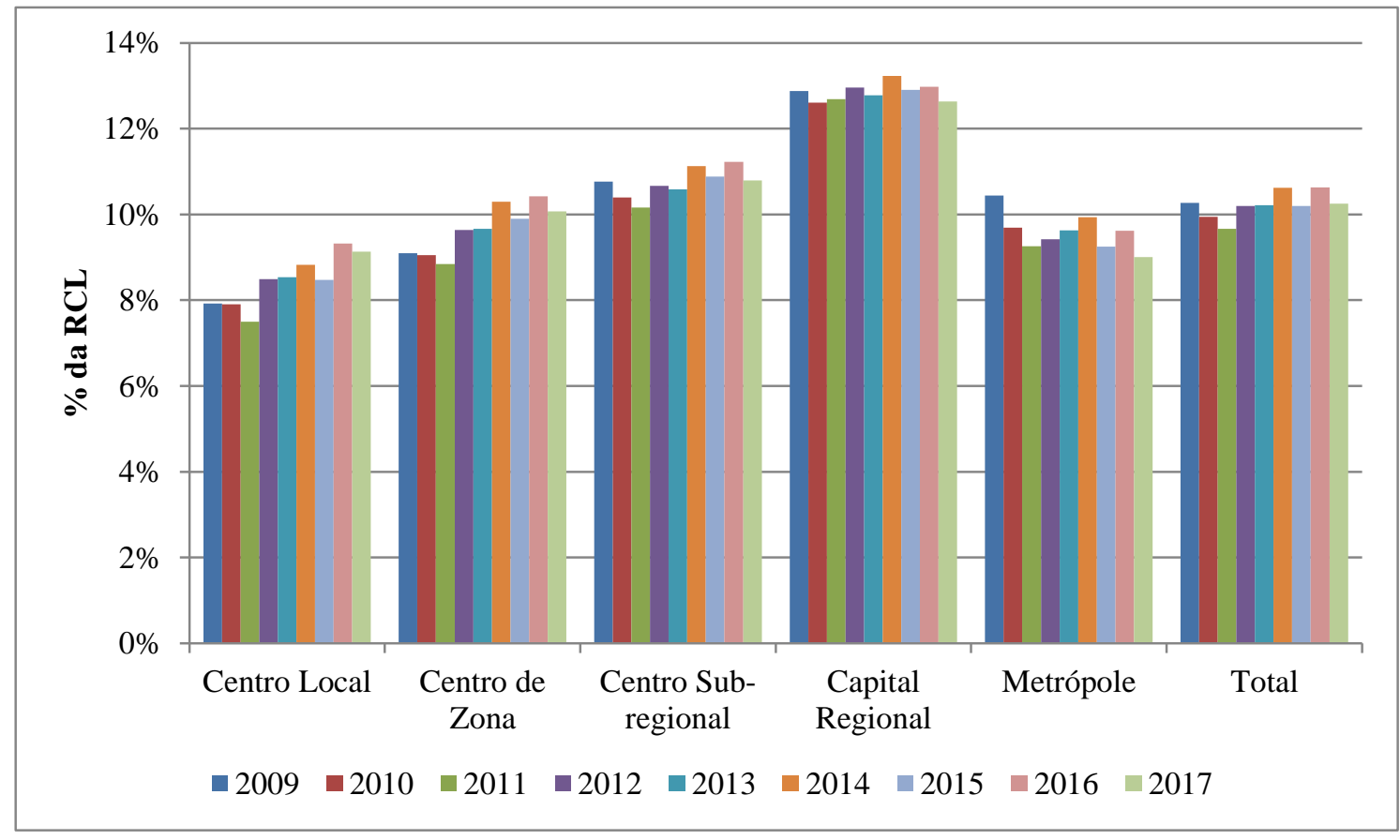

5. Acerca dos Índices da Regra de Ouro e de Operações de Crédito, o comportamento de maior relevância no orçamento dos municípios de hierarquias superiores pode estar relacionado ao fato destes, normalmente, apresentarem maior demanda por projetos de investimentos de grande porte, que demandam relativamente mais recursos de empréstimos. Uma segunda explicação é o fato de que poucos municípios são elegíveis a realizar operações de crédito. Segundo STN (2019), em 2019, 1.527 (mil quinhentos e vinte e sete) municípios não tinham dados disponíveis para que o Tesouro pudesse calcular a CAPAG. Entre os municípios que foram classificados no rating, apenas 1.642 (mil seiscentos e quarenta e dois) apresentaram notas A ou B, que tornam a localidade elegível para realizar a operação de crédito com aval do Tesouro. Em anos anteriores, esse grupo apto a tomar empréstimo era ainda menor - por exemplo, 1.314 (mil trezentos e quatorze) em 2018. Vale atentar ainda que a maior parte dos municípios elegíveis, estão nas hierarquias superiores, o que contribui para esse comportamento dos indicadores IRO e IOC observados no Gráfico 1. 


\section{CONSIDERAÇÕES FINAIS}

Esse artigo buscou estabelecer, a partir da construção de indicadores fiscais, um padrão de financiamento dos municípios brasileiros, agrupados de acordo com a classificação da hierarquia de centros urbanos do IBGE. Para alcançar tal objetivo foi construída uma base de dados balanceada, com quase 4 (quatro) mil municípios em um intervalo de tempo de 9 (nove) anos a contar de 2009. Após a segmentação desses municípios em cinco grupos de acordo com sua classificação na hierarquia urbana, foram calculados os indicadores de financiamento propostos por Cialdini e Afonso (2014).

Os resultados obtidos com o levantamento são consistentes com evidencias apontadas pela literatura econômica prévia, como, por exemplo, a notável dependência de transferências nos municípios de menor porte, o maior aproveitamento da base de arrecadação nos grandes centros urbanos e a utilização de instrumentos de crédito pelas cidades maiores, que usualmente executam grandes projetos de investimento. Um resultado apontado por esse levantamento que é inédito, diz respeito ao à tendência de haver menor grau de liquidez (para compromissos financeiros de curto prazo) nos municípios mais avançados dentro da escala urbana.

Apesar de o trabalho ter apresentado dados para um intervalo de tempo razoável, não foi possível estabelecer alguma relação entre eles e o ciclo econômico ou político (eleitoral). Apesar da segunda década do século XXI tem sido marcada pela crise econômica e política, não é possível notar um impacto desse evento sobre esses padrões de financiamento identificados no artigo. Aparentemente, os padrões dependem mais de fatores estruturais (econômicos e institucionais) do que do ciclo econômico.

Do ponto de vista normativo, os resultados do artigo lançam luz sobre alguns pontos que merecem destaque nas agendas de reforma estruturantes atualmente discutidas no Brasil. A grande dispersão do padrão de financiamento das prefeituras, aliada ao regular aumento das responsabilidades locais na condução das políticas públicas e à crise fiscal nos últimos anos, abre uma janela de oportunidade para se discutir uma revisão do pacto federativo, com especial ênfase na revisão de competências municipais (por porte) e no avanço de instrumentos de incentivo à cooperação dentro da federação. A reforma tributária é outra agenda importante que pode aproveitar os resultados desse artigo, na medida em que o impacto de uma mudança estrutural no sistema de arrecadação de receitas fiscais seria amplamente díspar no âmbito dos municípios.

\section{REFERÊNCIAS}

AFFONSO, Rui de Britto Álvares. Descentralização e reforma do Estado: a Federação brasileira na encruzilhada. Economia e Sociedade, Campinas, v. 9, n. 1, p.127-152, jun. 2000.

AFONSO, José Roberto R.; ARAUJO, Erika Amorim. A Capacidade de Gasto dos Municípios Brasileiros: Arrecadação Própria e Receita Disponível. Cadernos de Finanças Públicas, Brasília, v. 1, n. 1, p.19-30, dez. 2000. 
AFONSO, José Roberto R.; CASTRO, Kleber Pacheco de. Carga Tributária Brasileira em Perspectiva Histórica: Estatísticas Revisitadas. Rio de Janeiro, 2018. 22 p. (mimeo)

BREGMAN, Daniel. Reforma tributária e mudança no critério de distribuição da cota-parte do ICMS: compatibilidade e impacto nos orçamentos municipais. Revista do BNDES, Rio de Janeiro, n. 35, p.229-282, jun. 2011.

CASTRO, Kleber Pacheco de. Uma Avaliação do Fundo de Participação dos Estados sob a Ótica da Equalização Fiscal. 170 p. Tese (Doutorado em Economia) - Universidade do Estado do Rio de Janeiro, Rio de Janeiro, 2019.

CASTRO, Kleber Pacheco de; AFONSO, José Roberto R. Gasto social no Brasil pós-1988: uma análise sob a ótica da descentralização fiscal. Política, Planejamento e Gestão em Saúde, [s.I.], v. 1, n. 1, p.33-56, dez. 2010.

CASTRO, Kleber Pacheco de; LIMA, Ana Carolina da Cruz. Avaliação da distribuição do FPM: uma aplicação da teoria dos conjuntos fuzzy para os municípios de Minas Gerais. In: ENCONTRO NACIONAL DA ASSOCIAÇÃO BRASILEIRA DE ESTUDOS REGIONAIS E URBANOS, 15, 2017, São Paulo. Anais... . São Paulo: ABER, 2017. p. 1-21.

CIALDINI, Alexandre S.; AFONSO, José Roberto Afonso. Os Municípios e a Lei de Responsabilidade Fiscal: de conceitos a indicadores. Rio de Janeiro: mimeo, 2014. $23 \mathrm{p}$.

COSSIO, Fernando Andrés Blanco. Ensaios sobre Federalismo Fiscal no Brasil. 2002. 169 f. Tese (Doutorado) - Curso de Economia, PUC-RJ, Rio de Janeiro, 2002.

COURI, Daniel et al. Regra de Ouro no Brasil: Balanço e Desafios. Brasília: IFI, 2018. 46 p. (Estudo Especial no 5).

FERNANDES, Antônio Sérgio Araújo; WILSON, Robert H.. Mudança institucional e gestão metropolitana no Brasil: o municipalismo autárquico e as finanças municipais metropolitanas. Revista de Administração Pública, [s.l.], v. 47, n. 3, p.777-800, jun. 2013. http://dx.doi.org/10.1590/s0034-76122013000300011.

GOMES, Gustavo M.; MACDOWELL, Maria C. Descentralização Política, Federalismo Fiscal e Criação de Municípios: 0 que é Mau para o Econômico nem Sempre é Bom para o Social. Brasília: Ipea, 2000. 27 p. (Texto para Discussão no 706).

INSTITUTO BRASILEIRO DE GEOGRAFIA E ESTATÍSTICA. Regiões de influência das cidades - 2007. Rio de Janeiro: IBGE, 2008.201 p. MARSHALL, Alfred. Princípios de Economia. São Paulo: Nova Cultural, 1996. 368 p.

MILES, Ian. Services in the new industrial economy. Futures, [s.I.], v. 25, n. 6, p.653-672, jul. 1993. http://dx.doi.org/10.1016/00163287(93)90106-4.

PELLEGRINI, Josué Alfredo. A nova metodologia de cálculo da capacidade de pagamento dos estados e municípios. Brasília: IFI, 2017. 46 p. (Nota Técnica no 13).

PIOLA, Sérgio Francisco. Transferências de recursos federais do Sistema Único de Saúde para Estados, Distrito Federal e Municípios: Os desafios para a implementação dos critérios da Lei Complementar no 141/2012. Brasília: Ipea, 2017. 42 p. (Texto para Discussão no 2298).

SANTOS, Angela Penalva dos; CASTRO, Kleber Pacheco de. Local Governments' Tax Burden in Brazil: Evolution and Characteristics. In: IWIN-GARZYńSKA, Jolanta (Ed.). Taxes and Taxation Trends. London: IntechOpen, 2018. Cap. 13. p. 245-262.

SECRETARIA DO TESOURO NACIONAL. Boletim de Finanças dos Entes Subnacionais - 2019. Brasília: STN, 2019. 140 p. (Edição de Agosto/2019).

SECRETARIA DO TESOURO NACIONAL. Fundo de Participação dos Estados e do Distrito Federal - FPE. Brasília: STN, 2018. 13 p. (O que você precisa saber sobre as transferências fiscais da União).

SERRA, José; AFONSO, José Roberto R. El federalismo fiscal en Brasil: una visión panorámica. Revista de la CEPAL, Santiago, v. 91 , p. 29-52, abr. 2007.

TRISTÃO, José Américo Martelli. A administração tributária dos municípios brasileiros: uma avaliação do desempenho da arrecadação. 172 p. Tese (Doutorado em Administração) - Escola de Administração e Empresas de São Paulo, São Paulo, 2003.

VARSANO, Ricardo. A evolução do sistema tributário brasileiro ao longo do século: Anotações e reflexões para futuras reformas. Rio de Janeiro: Ipea, 1996. 34 p. (Texto para Discussão no 405).

VARSANO, Ricardo et al. Uma Análise da Carga Tributária no Brasil. Rio de Janeiro: Ipea, 1998. 55 p. (Texto para Discussão no 583). 